Basic Solid Mechanics 
Other engineering titles of related interest

Automation with Programmable Logic Controllers

Peter Rohner

Design and Manufacture

An Integrated Approach

Rod Black

Dynamics

G.E. Drabble

Elementary Engineering Mechanics

G.E. Drabble

Finite Elements

A Gentle Introduction

D. Henwood and J. Bonet

Fluid Mechanics

Martin Widden

Introduction to Engineering Materials

V.B. John

Introduction to Internal Combustion Engines, Second Edition Richard Stone

Mechanics of Machines, Second Edition

G.H. Ryder and M.D. Bennett

Thermodynamics

J. Simonson 


\title{
Basic Solid Mechanics
}

\author{
D.W.A. Rees
}

Department of Manufacturing and Engineering Systems, Brunel University 
All rights reserved. No reproduction, copy or transmission of this publication may be made without written permission.

No paragraph of this publication may be reproduced, copied or transmitted save with written permission or in accordance with the provisions of the Copyright, Designs and Patents Act 1988, or under the terms of any licence permitting limited copying issued by the Copyright Licensing Agency, 90 Tottenham Court Road, London W1P 9HE.

Any person who does any unauthorised act in relation to this publication may be liable to criminal prosecution and civil claims for damages.

The author has asserted his rights to be identified as the author of this work in accordance with the Copyright, Designs and Patents Act 1988.

First published 1997 by MACMILLAN PRESS LTD

Houndmills, Basingstoke, Hampshire RG21 6XS

and London

Companies and representatives

throughout the world

ISBN 978-0-333-66609-8 ISBN 978-1-349-14161-6 (eBook) DOI 10.1007/978-1-349-14161-6

A catalogue record for this book is available from the British Library.

This book is printed on paper suitable for recycling and made from fully managed and sustained forest sources.

$\begin{array}{rrrrrrrrrr}10 & 9 & 8 & 7 & 6 & 5 & 4 & 3 & 2 & 1 \\ 06 & 05 & 04 & 03 & 02 & 01 & 00 & 99 & 98 & 97\end{array}$




\section{Contents}

Preface

List of Symbols

viii

$\mathbf{x}$

Chapter 1 Overview

1.1 Role of Solid Mechanics in Design 1

1.2 Units and Conventions 1

1.3 Elasticity 3

1.4 Structures 4

1.5 Yielding 6

1.6 Final Remarks 6

$\begin{array}{llr}\text { Chapter } 2 & \text { Static Equilibrium } & 8\end{array}$

2.1 Co-Planar, Concurrent Forces 8

2.2 Co-Planar, Non-Concurrent Forces 10

2.3 The Free Body Diagram 15

2.4 Bar Forces in Plane Frames 17

2.5 Forces and Moments in Beams 19 Exercises 26

Chapter 3 Basic Stress and Strain 33

3.1 Direct Stress and Strain 33

3.2 Shear Stress and Strain 36

3.3 Compound Bars 41

3.4 Temperature Effects $\quad 45$

Exercises 49

Chapter 4 Elasticity $\quad 56$

4.1 Elastic Constants $\quad 56$

4.2 Analysis of Pure Shear 59

4.3 Relationships Between Elastic Constants 62

4.4 Extended Hooke's Law 64

4.5 Thin-Walled Pressure Vessels 67

4.6 Thick-Walled Pressure Vessels 73

Exercises $\quad 79$ 
Chapter 5 Bending and Shear 83

5.1 Direct Stress in Bending 83

5.2 Combined Bending and Direct Stress 87

5.3 Bending of Composite Beams 93

5.4 Shear Stress Due to Shear Force 103 Exercises 108

Chapter 6 Deflections and Slopes of Beams 116

6.1 Differential Equation of Flexure 116

6.2 Mohr's Theorems 120

6.3 Macaulay's Method 130

6.4 Superposition Principle 135

Exercises 143

Chapter 7 Theories of Torsion 148

7.1 Torsion of Circular Bars 148

7.2 Torsion of Thin Strips 157

7.3 Bredt-Batho Torsion Theory 167

Exercises $\quad 182$

Chapter 8 Buckling of Struts 190

8.1 Euler Theory 190

8.2 Imperfect Euler Struts 194

8.3 Semi-Empirical Formulae 207

Exercises $\quad 219$

Chapter 9 Strain Energy 225

9.1 Internal Energy and External Work 225

9.2 Strain Energy Expressions 228

9.3 Application to Springs 239

9.4 Impact Loading 249

9.5 Castigliano's Theorems 252

Exercises 262

Chapter 10 Stress and Strain Analyses $\quad 269$

10.1 Plane Stress Analysis 269

10.2 Mohr's Circle 279

10.3 Matrix Method 283

10.4 Plane Strain Analyses 285

Exercises 294 
Chapter 11 Theories of Strength

11.1 Yielding of Ductile Metals 299

11.2 Principal Biaxial Stress 309

11.3 Combined Axial and Shear Stresses 313

11.4 Failure Criteria for Brittle Solids 320

References $\quad 327$

Exercises $\quad 328$

Chapter 12 The Stiffness Matrix 337

12.1 Introduction 337

12.2 Energy Methods 338

12.3 Bar Element Under Axial Stress 341

12.4 Torsion Element 352

12.5 Beam Element 355

Exercises $\quad 367$

Appendix Properties of Areas 369

A.1 The Centroid and Moments of Area 369

A.2 Parallel and Perpendicular Axes 370

A.3 Principal Second Moments of Area 377

A.4 Graphical Solution to $I_{u}$ and $I_{v}$

A.5 Matrix Method 386

Exercises $\quad 388$

$\begin{array}{ll}\text { Index } & 391\end{array}$ 


\section{Preface}

This book has been compiled from lecture notes and examples that I have used in my teaching of solid mechanics, strength of materials and structures over many years. It is intended for undergraduate engineering courses in which statics, solid mechanics and structures are taught to an intermediary level. The contents should serve most courses in mechanical, civil, aeronautical and materials engineering. The approach employed is to intersperse theory with many illustrative examples and exercises. As readers work through these they should soon realise the engineer's interest in solid mechanics. They will see that all calculations made are related to the load carrying capacity and the deformation of materials used in engineering design. Among the design considerations are: the choice of material, its physical shape, the nature of imposed loading and its effect on the internal stress and strain. The loadings refer to: tension, compression, bending, torsion and shear. Typical structures to which these loadings are applied include: bars, columns, struts, tubes, vessels, beams, springs and frames.

The analyses of stress, strain, load and deflection employ various techniques with which the reader should soon become familiar. Among these are: Mohr's circle, the free-body diagram, Hooke' law, Macaulay's method and Castigliano's theorems. The text illustrates where and how best to employ each technique within a logical presentation of the subject matter.

In general, a unique solution to a problem in solid mechanics will satisfy equilibrium, compatibility and the boundary conditions. Throughout this book the three conditions have been satisfied to provide closed solutions. However, it may not always be possible to achieve this as the loading and geometry become more complex. The final chapter shows how the known stiffness matrix for three different finite elements can be embodied within a numerical solution to displacement, stress and strain. The three aforementioned conditions are satisfied but, because it is necessary to assume a displacement function, the solutions found are close approximations. Finite elements can offer no advantage where closed solutions exist.

An overview of the contents is given in Chapter 1. There the reader will also find a tribute to those early engineers and men of science who are responsible for shaping this subject into the form in which it is taught 
today. They have provided us with the techniques and a system of units with which to define the subject.

Exercise sections have been compiled by the author to support the topics within each chapter. They have been derived mostly from past examination papers. Acknowledgements are due to Brunel University, Kingston University and to the. Council of Engineering Institutions for granting permission to include questions from their past examination papers both as worked examples and exercises.

D.W.A. Rees 


\section{List of Symbols}

$\begin{array}{ll}\mathbf{a}, \mathbf{f}, \mathbf{A}, \mathbf{B}, \mathbf{C}, \mathbf{R}, \mathbf{V} & \text { force vectors } \\ \mathbf{E}, \mathbf{E}^{\prime} & \text { strain matrices } \\ \mathbf{K} & \text { stiffness matrix } \\ \mathbf{L} & \text { rotation matrix } \\ \mathbf{M}, \mathbf{T} & \text { matrices of direction cosines } \\ \mathbf{S}, \mathbf{S}^{\prime} & \text { stress matrices } \\ \mathbf{d} & \text { displacement vector } \\ a, l, L & \text { lengths } \\ A & \text { section area, enclosed area } \\ b, d, e, s & \text { dimensions } \\ B, C, F, R, p & \text { forces } \\ d, D & \text { bar diameters } \\ E, G, K & \text { elastic constants } \\ F & \text { shear force } \\ F_{i j} & \text { flexibility components } \\ h, k & \text { force locations } \\ i, D & \text { first moment of area } \\ I & \text { second moment of area } \\ J & \text { polar moment of area } \\ J_{1}{ }^{\prime}, J_{2}{ }^{\prime}, J_{3}{ }^{\prime} & \text { stress deviator invariants } \\ k & \text { radius of gyration, shear yield stress } \\ K_{i j} & \text { stiffness coefficients } \\ M & \text { bending moment } \\ n & \text { hardening exponent } \\ N & \text { rotational speed } \\ p & \text { pressure, pitch } \\ P & \text { applied force, power } \\ q & \text { shear flow } \\ Q & \text { heat work transfer } \\ r, \theta, z & \text { polar co-ordinates } \\ R & \text { radius of curvature } \\ S & \text { safety factor } \\ t & \text { thickness, temperature } \\ T & \text { torque } \\ u & \text { radial displacement, strain energy density } \\ U & \text { strain energy stored } \\ v & \text { lateral strut deflection } \\ & \end{array}$




$\begin{array}{ll}V & \text { volume } \\ w & \text { distributed loading, warping displacement } \\ W & \text { work transfer, applied load } \\ x & \text { extension } \\ x, y, z & \text { cartesian co-ordinates } \\ \bar{x}, \bar{y}, \bar{z} & \text { centroid locations } \\ y & \text { distance from neutral axis } \\ Y & \text { tensile yield stress } \\ \alpha & \text { coefficient of expansion, helix angle } \\ \beta, \theta & \text { inclinations } \\ \delta, \Delta & \text { load point displacements } \\ \varepsilon & \text { direct strain } \\ \gamma & \text { shear strain } \\ \phi & \text { shear distortion, rotation } \\ v & \text { Poisson's ratio } \\ \sigma & \text { direct stress } \\ \sigma_{m} & \text { mean stress } \\ \sigma_{c} & \text { compressive yield stress } \\ \sigma^{\prime} & \text { deviatoric stress } \\ \tau & \text { shear stress }\end{array}$

\section{Subscripts and superscripts}

$\begin{array}{ll}c & \text { compression } \\ e & \text { element } \\ E & \text { Euler, equivalent, external } \\ i, j & \text { tensor notation, components of a matrix } \\ I & \text { internal } \\ k & \text { components of a vector quantity } \\ m & \text { mean or hydrostatic } \\ o & \text { octahedral } \\ r, \theta & \text { polar components } \\ s & \text { shear component, solid } \\ T & \text { transpose of a matrix } \\ v & \text { volumetric component } \\ x, y & \text { cartesian components } \\ , & \text { co-ordinate rotation, deviatoric } \\ * & \text { complementary measure } \\ 1,2 & \text { principal values }\end{array}$




\section{Abbreviations}

e.t.b.

e.t.t.

NA

PS

PVW

SPE

UBS

UCS

UTS engineer's theory of bending engineer's theory of torsion neutral axis

proof stress

principle of virtual work stationary potential energy

ultimate bearing strength ultimate compressive strength ultimate tensile strength 